\title{
Acute Kidney Injury in COVID-19: Another Challenge for Nephrology
}

\author{
Michael R. Rudnick Rachel Hilburg \\ Nephrology Division, Perelman School of Medicine of the University of Pennsylvania, Philadelphia, PA, USA
}

\section{Keywords \\ COVID-19 · SARS-CoV-2 · Acute kidney injury $\cdot$ Renal replacement therapy $\cdot$ Dialysis}

As of August 16, 2020, there have been 21,294,845 cases of COVID-19 worldwide with 761,779 deaths [1]. Initial reports of COVID-19 focused on the severe acute respiratory syndrome seen in these patients. Early on in the pandemic, however, it became apparent that many COVID-19 patients also displayed kidney abnormalities, primarily acute kidney injury (AKI). There are several observations which suggest that the severe acute respiratory syndrome coronovirus 2 (SARS-CoV-2) responsible for COVID-19 may be capable of producing unique pathophysiological pathways responsible for the AKI observed in these patients [2].

One mechanism put forth is tropism for angiotensinconverting enzyme 2 receptors present on cells of the proximal tubule and to a lesser extent on podocytes, which raises the possibility of direct cell entry and injury. Although there are reports of viral particles in kidney tissue specimens, definitive proof that these inclusions are SARS-CoV-2 have not been demonstrated. Other mechanisms for SARS-CoV-2-mediated renal injury include prothrombotic coagulopathy, the release of nephrotoxic mediators from cytokine storm, and an imbalance of the renin-angiotensin-aldosterone system with detrimental hemodynamic effects [2].

$\begin{aligned} & \text { karger@karger.com } \\ & \text { www.karger.com/ajn }\end{aligned}$
Karger $\%$

A limited number of postmortem and kidney biopsy studies in COVID-19 patients, many of whom had AKI, demonstrate that the most commonly observed pathology was that of acute tubular injury (ATI). This finding is not surprising given that many of these patients experience hemodynamic instability, periods of hypoxemia, sepsis, and exposure to drugs with known nephrotoxic potential. Another finding is that some patients demonstrated collapsing focal segmental glomerulosclerosis. This pathology may be primarily limited to African American patients, and in some cases, genetic testing demonstrated the presence of APOL1 high-risk genotypes [3]. Less commonly reported findings include pigmented casts consistent with rhabdomyolysis, immunemediated glomerular nephritis, and thrombotic microangiopathy.

Currently, a number of published studies describe hospitalized patients with COVID-19 and AKI [4]. The incidence of AKI in these studies varies widely likely due to differences in criteria for hospital admission, definition of AKI, ethnicities, and other variables. The studies also have considerable heterogeneity among demographic characteristics, severity, risk factors, morbidities, and mortalities. In this issue of the American Journal of Nephrology, Zahid and colleagues performed a detailed retrospective analysis of AKI in 469 COVID-19 patients admitted to Brookdale University Hospital in Brooklyn, NY, of whom $27.1 \%$ developed this complication during 
Table 1. Studies of AKI in COVID-19 patients in the USA

\begin{tabular}{|c|c|c|c|c|c|c|c|c|c|c|c|c|}
\hline \multirow[t]{2}{*}{ Author } & \multicolumn{3}{|c|}{ Study characteristics } & \multicolumn{3}{|c|}{ AKI severity, \% } & \multicolumn{3}{|c|}{ AKI in ICU patients, \% } & \multicolumn{3}{|c|}{ Mortality, \% } \\
\hline & $\begin{array}{l}\text { \# COVID } \\
\text { patients }\end{array}$ & $\begin{array}{l}\text { AKI, } \\
\%\end{array}$ & $\begin{array}{l}\text { Black race, } \\
\%\end{array}$ & $\begin{array}{l}\text { stage } \\
1-2\end{array}$ & stage 3 & RRT & $\begin{array}{l}\text { total } \\
\text { AKI }\end{array}$ & stage 3 & $\begin{array}{l}\text { on vent } \\
\text { requiring } \\
\text { RRT }\end{array}$ & all AKI & no AKI & $\begin{array}{l}\text { stage 3/ } \\
\text { RRT AKI }\end{array}$ \\
\hline Hirsch et al. [6] & 5,449 & 36.6 & 20.6 & 68.9 & 31.1 & 14.3 & 76 & 46.7 & 23.2 & 34.8 & 5.6 & 54 \\
\hline Chan et al. [7] & 3,235 & 43.5 & 25.3 & 55 & 45 & 20 & 68 & 63 & 34 & 45 & 7 & $\begin{array}{l}52 \% \text { in ICU } \\
( \pm \text { RRT })\end{array}$ \\
\hline Mohamed et al. [8] & 575 & 28 & 75 & 34 & 66 & 55 & 61 & 73 & $\mathrm{n} / \mathrm{a}$ & 50 & na & 72 \\
\hline Suleyman et al. [9] & 355 & 44.7 & 72 & na & na & na & 69.5 & na & $\mathrm{Na}$ & na & na & na \\
\hline Zahid et al. [5] & 469 & 27.3 & 77.3 & 49.2 & 50.8 & 17.2 & $68^{a}$ & $72^{\mathrm{a}}$ & 19 & 71.1 & 28.4 & 87.7 \\
\hline
\end{tabular}

AKI, acute kidney injury; RRT, renal replacement therapy. ${ }^{\text {a }}$ Percent in ventilated patient.

hospitalization [5]. One of the unique features of this report is that Brookdale University Hospital typically treats minority group patients from a low socioeconomic status, which is significant given observations that clinical outcomes with COVID-19 in minorities have been repeatedly reported to be worse than other groups. In this regard, $72.7 \%$ of the cohort studied by Zahid were African Americans and $14.3 \%$ were Hispanics. On admission, $44.1 \%$ of patients had an eGFR $<60 \mathrm{~mL} / \mathrm{min} / 1.73 \mathrm{~m}^{2}$ and $21.3 \%$ had a systolic blood pressure $<100 \mathrm{~mm} \mathrm{Hg}$. These observations raise the possibility that some of the patients with a reduced eGFR on admission were already in AKI, and thus, the incidence of AKI in this cohort was even greater than $27.1 \%$. Another concerning observation was that $50.8 \%$ of the patients who developed AKI during hospitalization had Stage 3 AKI. This observation is consistent with the high acuity level of COVID-19 AKI patients - 26\% had systolic blood pressure $<100 \mathrm{~mm} \mathrm{Hg}$ and 53\% required mechanical ventilation. Overall, $17 \%$ of all AKI patients required renal replacement therapy (RRT). For COVID-19 patients requiring mechanical ventilation, $68 \%$ developed AKI, and of this group $28 \%$ required RRT. COVID-19 AKI patients who required RRT was primarily $(86 \%)$ limited to patients requiring mechanical ventilation. The overall mortality in the entire cohort of COVID-19 patients was $40.1 \%$ but increased to $71.1 \%$ in those with AKI. Even more disconcerting were the observations that mortality rates in Stage 3 AKI with and without RRT were 81.8 and $90.7 \%$, respectively. The higher mortality in this latter group is likely due to the decision to initiate comfort care in many of these severely ill patients. Finally, assessment of kidney function recovery was limited to observations during the hospitalization full or partial recovery was seen in only $27 \%$. This low recovery rate was likely influenced by the high mortality rate in the COVID-19 AKI patients.

The study by Zahid and colleagues contributes to several other studies which have examined the incidence, clinical characteristics, and mortality in patients with COVID-19 and associated AKI in the United States (Table 1). Several key observations from these studies regarding AKI in COVID-19 have emerged. First, AKI in COVID-19 patients is common with incidences ranging from 27 to $45 \%$. Incidences of AKI are likely even higher based on the presumption that some of the patients with elevated serum $\mathrm{Cr}$ ( $\mathrm{SCr}$ ) on admission were already in AKI. In COVID-19 patients admitted to the ICU, the incidence of AKI is even greater, ranging from 61 to $76 \%$. Second, AKI in COVID-19 patients is frequently severe - 31-66\% of AKI patients have Stage 3 AKI, and $14-55 \%$ of cases require RRT, although the $55 \%$ observation is an outlier for unclear reasons [8]. In addition, $19-34 \%$ of ventilated patients required RRT. These observations are useful in strategic planning for resources such as CRRT machines. Third, COVID-19 patients with AKI have a high mortality ranging from 35 to $71 \%$ and mortality is even higher in stage 3 AKI patients ranging from 52 to $88 \%$ regardless of RRT usage. In comparison, the mortality rates in COVID-19 hospitalized patients without AKI are in most cases much lower, around 6\%. Finally, consistent with observations of increased COVID-19 morbidity and mortality in minorities, the studies of Zahid et al. [5] and Mohamed et al. [8] also demonstrate that AKI in minorities with COVID-19 is more severe and associated with an increased mortality compared to non-minority populations.

Despite the emergence of a clearer picture of AKI in hospitalized patients in the United States infected with 
SARS-CoV-2, several questions still remain unanswered. ATI appears to be the most commonly seen histologic finding in COVID-19 AKI and is frequently due to the usual precipitating events (hemodynamic instability, sepsis, and nephrotoxin exposure) typically seen in critically ill patients. However, it remains unclear if COVID-19 features of hypercoagulability and cytokine storm as well as the presence of AT2 receptors on proximal tubular epithelial cells predispose to either an increased susceptibility to ATI or in some cases other pathologic presentations such as collapsing focal segmental glomerulosclerosis [2]. The studies performed to date have been limited to observations during hospitalization, so the burden of residual kidney damage remains unknown in COVID-19 patients with AKI who survive hospitalization. Considering that the AKI in many of these patients is severe and often requires RRT, it is not unreasonable to speculate that some surviving patients will be left with new or worsened CKD. In addition, given the very high mortality in COVID-19 patients with stage $3 \mathrm{AKI}$, the question arises if physicians should be more aggressive in seeking palliative care consultation once this complication develops. Finally, as physicians gain knowledge in how to more effectively manage severely ill COVID-19 patients and new therapeutics for infection with SARS-CoV-2 become available, there may be a differential effect on the currently observed incidence, severity, and mortality of AKI in patients with COVID-19. Our knowledge of COVID-19 is rapidly expanding, but one observation that has become very clear is that AKI is common in patients with severe COVID-19 disease and as such presents numerous challenges for nephrologists.

\section{Conflict of Interest Statement}

No conflicts of interest for either Drs. Hilburg or Rudnick.

\section{References}

1 Available from: https://www.who.int/docs/ default-source/coronaviruse/situationreports/20200816-covid-19-sitrep-209. pdf?sfvrsn $=5$ dde1ca2 $\_2$ Accessed 2020 Aug 16.

2 Battle D, Soler MJ, Sparks MA, Hiremath S, South AM, Welling PA, et al. Acute kidney injury in COVID-19: emerging evidence of a distinct pathophysiology. J Am Soc Nephrol. 2020;31(7):1380-3.

3 Kudose S, Batal I, Santoriello D, Xu K, Barasch J, Peleg Y, et al. Kidney biopsy findings in patients with COVID-19. J Am Soc Nephrol. 2020;31(9):1959-68.
4 Farouk SS, Fiaccadori E, Cravedi P, Campbell KN. COVID-19 and the kidney: what we think we know so far and what we don't. J Nephrol. 2020;1-6.

5 Zahid U, Ramachandran P, Spitalewitz S, Alasadi L, Chakraborti A, Azhar M, et al. Acute kidney injury in COVID19 patients: an inner city hospital experience and policy implications. Am J Nephrol. 2020. DOI: 10.1159/000511160.

6 Hirsch JS, Ng JH, Ross DW, Sharma P, Shah $\mathrm{HH}$, Barnett RL, et al. Acute kidney injury in patients hospitalized with COVID-19. Kidney Int. 2020;98(1):209-18.

7 Chan L, Chaudhary K, Saha A, Chauhan K, Vaid A, Baweja M, et al. Acute kidney injury in hospitalized patients with COVID-19. medRxiv.
8 Mohamed MMB, Lukitsch I, Torres-Ortiz AE, Walker JB, Varghese V, Hernandez-Arroyo $\mathrm{CF}$, et al. Acute kidney injury associated with coronavirus disease 2019 in urban New Orleans. Kidney360. 2020;1(July):614-22.

9 Suleyman G, Fadel RA, Malette KM, Hammond C, Abdulla H, Entz A, et al. Clinical characteristics and morbidity associated with coronavirus disease 2019 in a series of patients in metropolitan detroit. JAMA Netw Open. 2020;3(6):e2012270. 